\title{
Antibodies Against Human BLyS and APRIL Attenuate EAE Development in Marmoset Monkeys
}

\author{
S. Anwar Jagessar • Nicole Heijmans • Jan Bauer • \\ Erwin L. A. Blezer • Jon D. Laman • Thi-Sau Migone • \\ Matt N. Devalaraja • Bert A. 't Hart
}

Received: 13 June 2012 / Accepted: 14 June 2012 /Published online: 30 June 2012

(C) The Author(s) 2012. This article is published with open access at Springerlink.com.

\begin{abstract}
B lymphocyte stimulator (BLyS, also indicated as BAFF (B-cell activating factor) and CD257), and A Proliferation Inducing Ligand (APRIL, CD256) are two members of the TNF superfamily with a central role in B cell survival. Antibodies against these factors have potential therapeutic relevance in autoimmune inflammatory disorders with a proven pathogenic contribution of B cells, such as multiple
\end{abstract}

Matt N. Devalaraja and Bert A. 't Hart share senior authorship

S. A. Jagessar $\cdot$ N. Heijmans $\cdot$ B. A. 't Hart $(\bowtie)$

Department Immunobiology,

Biomedical Primate Research Centre,

PO Box 3306, 2280 GH Rijswijk, The Netherlands

e-mail: hart@bprc.nl

S. A. Jagessar · J. D. Laman · B. A. 't Hart

ErasMS Center for Translational research into MS,

Rotterdam, The Netherlands

J. Bauer

Department of Neuroimmunology, Medical University Vienna,

Center for Brain Research,

Vienna, Austria

E. L. A. Blezer

Image Sciences Institute, University Medical Center Utrecht,

Utrecht, The Netherlands

J. D. Laman

Department of Immunology, Erasmus MC,

University Medical Center,

Rotterdam, The Netherlands

T.-S. Migone $\cdot$ M. N. Devalaraja

Human Genome Sciences,

Rockville, MD, USA

B. A. 't Hart

Department of Medical Physiology,

University Medical Centre Groningen,

Oosterparkwijk, The Netherlands sclerosis (MS). In the current study we performed a multiparameter efficacy comparison of monoclonal antibodies against human anti-BLyS and anti-APRIL in a common marmoset (Callithrix jacchus) model of experimental autoimmune encephalomyelitis (EAE). A MS-like disease was induced by immunization with recombinant human myelin/ oligodendrocyte glycoprotein (rhMOG) in complete Freund's adjuvant. The results show that the anti-BLyS and anti-APRIL antibody cause significant depletion of circulating CD20+ B cells, but a small subset of $\mathrm{CD} 20+\mathrm{CD} 40^{\text {high }} \mathrm{B}$ cells was not depleted. Induction of $\mathrm{CD} 20+\mathrm{B}$ cell depletion from lymph nodes was only observed in the anti-BLyS treated monkeys. Both antibodies had a significant inhibitory effect on disease development, but all monkeys developed clinically evident EAE. Anti-BLyS treated monkeys were sacrificed with the same clinical signs as saline-treated monkeys, but nevertheless displayed significantly reduced spinal cord demyelination. This effect was not observed in the anti-APRIL treated monkeys. The two antibodies had a different effect on $\mathrm{T}$ cell subset activation and the profiles of ex vivo released cytokines. In conclusion, treatment with anti-BLyS and anti-APRIL delays the development of neurological disease in a relevant preclinical model of MS. The two mAbs achieve this effect via different mechanisms.

Keywords Non-human primate $\cdot$ Multiple sclerosis $\cdot$ B-cell Depletion $\cdot$ Cytokines $\cdot$ EAE

\section{Introduction}

Multiple sclerosis (MS) is an inflammatory demyelinating disease of the human central nervous system (CNS). The disease is pathologically characterized by the presence of 
demyelinated lesions within the white as well as grey matter, which contain a variable degree of inflammation and damage to axons and neurons (Lassmann et al. 2007). Although demyelinated lesions are likely formed by the synergy of cellular and humoral immune mechanisms, most immunotherapies developed for MS target T cells (Lopez-Diego and Weiner 2008). The results of two recent clinical trials seem to have caused a paradigm shift in therapy development. Unexpectedly, treatment of relapsing/remitting MS (RRMS) patients using an antibody against human anti-IL12p40 aiming at the simultaneous inhibition of Th1 and Th17 $\mathrm{T}$ cell responses as demonstrated in psoriasis (Laws and Warren 2011), showed no detectable clinical benefit in RRMS (Segal et al. 2008). On the other hand, treatment of a similar group of patients with monoclonal antibodies against human CD20, causing profound and long lasting depletion of $\mathrm{B}$ cells, caused rapid and sustained suppression of neurological symptoms (Barun and Bar-Or 2012).

Total CD20+ B cell ablation is a highly effective manner to induce robust and long-lasting disease suppression in a variety of autoimmune disorders, including rheumatoid arthritis (RA), systemic lupus erythematosus (SLE) (Pers et al. 2008) and MS (Barun and Bar-Or 2012). However, the treatment spares plasma cells it causes impairment of the immune defence against new and latent infections. Occasional reactivation of hepatitis $\mathrm{B}$ and $\mathrm{C}$, and polyoma JC virus can give rise to serious clinical complications (Carson et al. 2009). This situation warrants the question whether profound systemic B cell depletion is indeed needed for the therapeutic effect or whether alternative B cell targeting treatments may be equally beneficial.

The primary aim of this study was to test the efficacy of two monoclonal antibodies, one for B Lymphocyte Stimulator (BLyS), also known as B-cell Activating Factor (BAFF, CD257) of the TNF family, and a second for A Proliferation-Inducing Ligand (APRIL, CD256). Both cytokines have an important role in the differentiation of B cells (Daridon et al. 2008). A secondary aim of the study was to obtain mechanistic information on the two antibodies by examining changes of autoimmune reactions. The efficacy of the two antibodies was tested in an experimental autoimmune encephalomyelitis (EAE) model in common marmosets (Callithrix jacchus), induced by immunization with recombinant human myelin/oligodendrocyte glycoprotein (rhMOG) formulated in complete Freund's adjuvant (CFA) (Brok et al. 2000; Kap et al. 2008). This rhMOG/CFA EAE model has been well established as a valid preclinical model of MS for translational research into immunopathogenic mechanisms and the preclinical evaluation of novel immunotherapies ('t Hart et al. 2011).

In a recent set of experiments we used HuMab 7D8, a novel fully human $\operatorname{IgG}$ monoclonal antibody $(\mathrm{mAb})$ that binds the same epitope on human CD20 as ofatumumab to examine the pathogenic contribution of $\mathrm{B}$ cells to this model (Teeling et al. 2004; Kap et al. 2010). We reported that the profound clinical effect antibody was caused by suppression of cellular and humoral autoimmune mechanisms that lead to lesion formation and neurological deficit (Kap et al. 2010; Kap et al. 2011).

In the here reported study we used essentially the same design for the efficacy testing of the anti-BLyS and antiAPRIL antibodies. Both antibodies induced depletion of CD20+ B-cells, which was reflected by suppressed autoantibody production and modulation of $\mathrm{T}$ cell proliferation and cytokine production. Both antibodies induced a significant delay of the disease onset. The clinical effect of the antiBLyS antibody was stronger than of the anti-APRIL antibody. Treatment with the anti-BLyS antibody also lowered demyelination of the spinal cord, whereas this was not observed in monkeys treated with the anti-APRIL antibody.

\section{Materials and methods}

\section{Animals}

Eighteen adult male common marmosets (Callithrix jacchus) were purchased from the outbred colony maintained at the Biomedical Primate Research Centre (Rijswijk, The Netherlands). Individual data of all monkeys used in this study are listed in Table 1. Before inclusion in the study the animals were subjected to a complete physical, haematological and biochemical examination. Only monkeys that were declared healthy by the institute's veterinarians were used. During the study they remained under veterinary care. Monkeys were pair-housed in spacious cages enriched with branches and padded shelter on the floor. Daily diet consisted of commercial food pellets of New World monkeys (Special Diet Serviced, Witham, Essex, UK), supplemented with raisins, peanuts, marshmallows, biscuits, fresh fruit, maggots and gum. Drinking water was provided ad libitum.

According to the Netherlands' law on animal experimentation, the procedures of this study was reviewed and approved by the institute's ethics committee before initiation of the experiments.

\section{Antigens}

Human MOG extracellular domain (rhMOG) was expressed as an unglycosylated recombinant protein in Escherichia coli and purified in the BPRC laboratory, as previously described (Kerlero de Rosbo et al. 1997; Smith et al. 2005). All synthetic peptides based on the human MOG sequence, which were used for in vitro assays, were purchased from Cambridge Research Biochemicals Limited (Cleveland, UK). 
Table 1 Overview of marmoset used in this study and the post-mortem MRI read-outs of white (WM) and grey (GM) matter lesions in one cerebral hemisphere

\begin{tabular}{|c|c|c|c|c|c|c|c|c|c|}
\hline \multirow[t]{3}{*}{ Group } & \multirow[t]{3}{*}{ Animal } & \multirow[t]{3}{*}{$\mathrm{DOS}^{\mathrm{a}}$} & \multirow[t]{3}{*}{$\mathrm{Age}^{\mathrm{b}}$} & \multicolumn{6}{|c|}{ MRI lesions } \\
\hline & & & & \multicolumn{2}{|c|}{ Volume $\left(\mathrm{mm}^{3}\right)$} & \multicolumn{2}{|l|}{$\mathrm{T}_{2}(\mathrm{sec})$} & \multicolumn{2}{|c|}{ MTR (\%) } \\
\hline & & & & WM & GM & WM & GM & WM & GM \\
\hline \multirow[t]{6}{*}{ Control } & M02061 & 30 & 102 & 0 & 0 & - & - & - & - \\
\hline & M05053 & 57 & 62 & 540.7 & 34 & 65.9 & 71.7 & 29.3 & 26.5 \\
\hline & M07052 & 40 & 41 & 0 & 0 & - & - & - & - \\
\hline & M08071 & 50 & 26 & 0 & 0 & - & - & - & - \\
\hline & M08103 & 45 & 25 & 0 & 0 & - & - & - & - \\
\hline & Mi010311 & 55 & 114 & 1.1 & 0 & 64.9 & - & 31.8 & - \\
\hline Mean \pm SD & & $46 \pm 10$ & $62 \pm 38$ & $270 \pm 382$ & $34 \pm \mathrm{n} / \mathrm{a}$ & $65 \pm 0.7$ & $72 \pm \mathrm{n} / \mathrm{a}$ & $31 \pm 2$ & $26 \pm \mathrm{n} / \mathrm{a}$ \\
\hline \multirow[t]{6}{*}{ Anti-BLyS } & Mi016 & 102 & 153 & 189.5 & 10.4 & 64.2 & 68 & 32.3 & 26.6 \\
\hline & M03163 & 93 & 82 & 0 & 0 & - & - & - & - \\
\hline & M05025 & 75 & 66 & 330.8 & 20.0 & 65.5 & 70.6 & 32.4 & 26.3 \\
\hline & M07088 & 79 & 45 & 0 & 19.6 & - & 70.1 & - & 27.6 \\
\hline & M08099 & 56 & 25 & 0 & 0 & - & - & - & - \\
\hline & M09017 & 52 & 19 & 398.6 & 54.7 & 68.1 & 75.2 & 30.7 & 25.3 \\
\hline Mean \pm SD & & $76 \pm 20$ & $65 \pm 49$ & $306 \pm 107$ & $26 \pm 20$ & $66 \pm 2$ & $71 \pm 3$ & $31 \pm 1$ & $27 \pm 2$ \\
\hline \multirow[t]{6}{*}{ Anti-APRIL } & M0169 & 64 & 108 & 170.7 & 13.4 & 68.1 & 73.6 & 30.4 & 24.7 \\
\hline & M08029 & 43 & 30 & 186.4 & 27.9 & 66.8 & 76.5 & 32.0 & 26.0 \\
\hline & M05049 & 94 & 62 & 28.7 & 1.1 & 60.7 & 72.5 & 35.0 & 28.8 \\
\hline & M07036 & 109 & 42 & 1.8 & 0 & - & - & 34.1 & - \\
\hline & M08092 & 52 & 25 & 0.4 & 0 & - & - & 32.3 & - \\
\hline & M09031 & 52 & 18 & 0 & 0 & - & - & - & - \\
\hline Mean \pm SD & & $69 \pm 26$ & $48 \pm 33$ & $78 \pm 93$ & $14 \pm 13$ & $62 \pm 5$ & $74 \pm 2$ & $33 \pm 2$ & $27 \pm 2$ \\
\hline
\end{tabular}

All animals were males

${ }^{\text {a }}$ Day of sacrifice

${ }^{\mathrm{b}}$ Age in months at the start of the experiment

EAE induction and clinical scoring

EAE was induced with $100 \mu \mathrm{g}$ of rhMOG emulsified in CFA as previously described (Kap et al. 2010). All animals were daily monitored for neurological signs using a standard scoring systems (Kap et al. 2008; Jagessar et al. 2010). Briefly, $0=$ no clinical signs; $0.5=$ apathy, loss of appetite, altered walking pattern without ataxia; $1=$ lethargy, anorexia, loss of tail tonus, tremor; $2=$ ataxia, optic disease; $2.5=$ paraparesis or monoparesis, sensory loss; $3=$ paraplegia or hemiplegia; $4=$ quadriplegia; $5=$ spontaneous death due to EAE. The clinical end-point for each monkey was score 3 and overt neurological symptoms were observed from score 2 .

\section{Experimental design}

The study protocol was identical to a prior efficacy evaluation of a fully human anti-CD20 antibody (HuMab7D8) in the same rhMOG/CFA model(Kap et al. 2010). The human
anti-BLyS antibody (Benlysta; also known as belimumab) and anti-APRIL antibodies were provided by Human Genome Sciences, Inc. (Rockville, MD). Binding affinities of the anti-BLyS and anti-APRIL mAbs with recombinant human and marmoset BLyS and APRIL were determined by BIAcore analysis. Anti-BLyS bound with similar affinity to human BLyS (Kd $447 \pm 30 \mathrm{pM})$ and marmoset BLyS (Kd 744 $\pm 32 \mathrm{pM}$ ), whereas binding of the anti-human APRIL mAb to marmoset APRIL (Kd $19.7 \pm 6.6 \mathrm{nM}$ ) was about 8-fold lower than to human APRIL (Kd 2.4 $\pm 1.4 \mathrm{nM})$.

All monkeys were randomized to three groups of 6 . AntiBLyS and anti-APRIL mAbs were administered intravenously at a dose of $10 \mathrm{mg} / \mathrm{kg}(1 \mathrm{ml} / \mathrm{kg})$ once a week from day 21 after immunization until the end of the study. The control group received buffered saline $(1 \mathrm{ml} / \mathrm{kg})$ also once per week from day 21 after immunization.

It is important to point out that the genetic heterogeneity of the marmoset implies a highly variable response of individual animals in the model at the clinical, pathological and 
immunological level. In agreement with guidelines by the institute's animal experimentation committee we used power calculation to assess the minimal group size for statistical evaluating the treatment on the disease course. An inherent problem of the genetic variation in the model is that underlying immunopathogenic mechanisms are variable and do not develop synchronously. For this reason robust statistical data for secondary disease parameters are often not obtained. This problem that is inherent to preclinical research with higher species has recently been discussed elsewhere (Bacchetti et al. 2011).

Post-mortem examination

Monkeys selected for necropsy were first deeply sedated by intramuscular injection of alfaxan $(10 \mathrm{mg} / \mathrm{kg}$ ) (Vétoquinol S.A., Magny-Vernois, France). After collection of the maximum venous blood (PBMC) in EDTA vacutainers, animals were euthanized by infusion of sodium pentobarbital (Euthesate ${ }^{\circledR}$, Aphormo, Duiven, The Netherlands). At necropsy brain and spinal were removed for (immuno)histological examination and magnetic resonance imaging (MRI). Secondary lymphoid organs were aseptically removed for preparation of mononuclear cell (MNC) cultures; axillary (ALN), inguinal (ILN), lumbar (LLN) lymph node and spleen as previously described (Jagessar et al. 2008; Jagessar et al. 2010; Kap et al. 2010; Jagessar et al. 2012b). Femur was collected for isolation of bone marrow (BM) cells. Number of leukocytes, neutrophils and lymphocytes in blood was measured on an automated haematology analyzer (Sysmex XT2000iV, Norderstedt, Germany).

$\mathrm{T}$ cells proliferation

Proliferation was tested on MNC isolated from venous blood (EDTA) every two weeks or at necropsy from spleen and secondary lymph nodes (ALN, ILN, LLN) against a panel of overlapping MOG peptides $(10 \mu \mathrm{g} / \mathrm{ml})$ and rhMOG $(10 \mu \mathrm{g} / \mathrm{ml})$. Proliferation was expressed as stimulation index (SI), which is defined as the ratio between $\left[{ }^{3} \mathrm{H}\right]$-thymidine incorporation in the stimulated versus unstimulated cultures (Jagessar et al. 2008). SI values above 2 were considered positive.

\section{MNC phenotyping}

MNC were phenotyped as previously described (Jagessar et al. 2010; Jagessar et al. 2012b) and proliferating cells identified via CFSE vital dye dilution (Kap et al. 2008). Flow cytometry data were collected on a FACS LSRII cytometer and analysed with the FACSDiva software 5.0 (BD Biosciences).
Cytokine profiling by ELISA

Supernatants of MNC cultures were collected after $48 \mathrm{~h}$ stimulation with rhMOG or a panel of overlapping MOG peptides. Supernatants were assayed according to manufacturer's instruction with commercial available ELISA kits for monkey IFN- $\gamma$, monkey TNF- $\alpha$ (U-Cytech, Utrecht, The Netherlands) and human IL-17A (eBioscience, San Diego, CA).

Quantitative PCR

Total RNA was extracted from PBMC, spleen and ALN using RNAeasy minikit (Qiagen, Hilden, Germany). Subsequently, cDNA was synthesized for qPCR using primer and probe combination according to the Universal Probe Library (Roche, Indianapolis, In) as previously described (Jagessar et al. 2012a). Transcript levels were normalized against the reference gene Abelson (ABL).

\section{Autoantibody detection}

Immune sera were tested for the presence of $\operatorname{IgM}$ and $\operatorname{IgG}$ antibodies binding rhMOG or a panel of overlapping 23-mer pMOG sequences with ELISA as previously described (Jagessar et al. 2010).

\section{Statistical analysis}

Data are presented as mean \pm sem. Statistical analysis was performed using the Mann-Whitney $U$ test. Survival was evaluated using Log-Rank test. $p$ values $\leq 0.05$ were considered significant.

\section{Results}

Induction of B cell depletion by anti-BLyS and anti-APRIL antibodies

Eighteen unrelated common marmosets were randomized to 3 groups of 6 animals each (see Table 1). EAE was induced in all animals by a single immunization with rhMOG in CFA. Treatment with anti-BLyS and antiAPRIL was started 21 days after the immunization, but before clinically evident EAE was observed. Both antibodies were administered as a weekly intravenous dose of $10 \mathrm{mg} / \mathrm{kg}(1 \mathrm{ml} / \mathrm{kg})$; the control group received the same volume of buffered saline.

We tested B cell depletion,by flow cytometric analysis of CD20 and CD40 expression on MNC, and qPCR analysis of CD19 mRNA transcripts (Kap et al. 2010). Figure 1a shows 

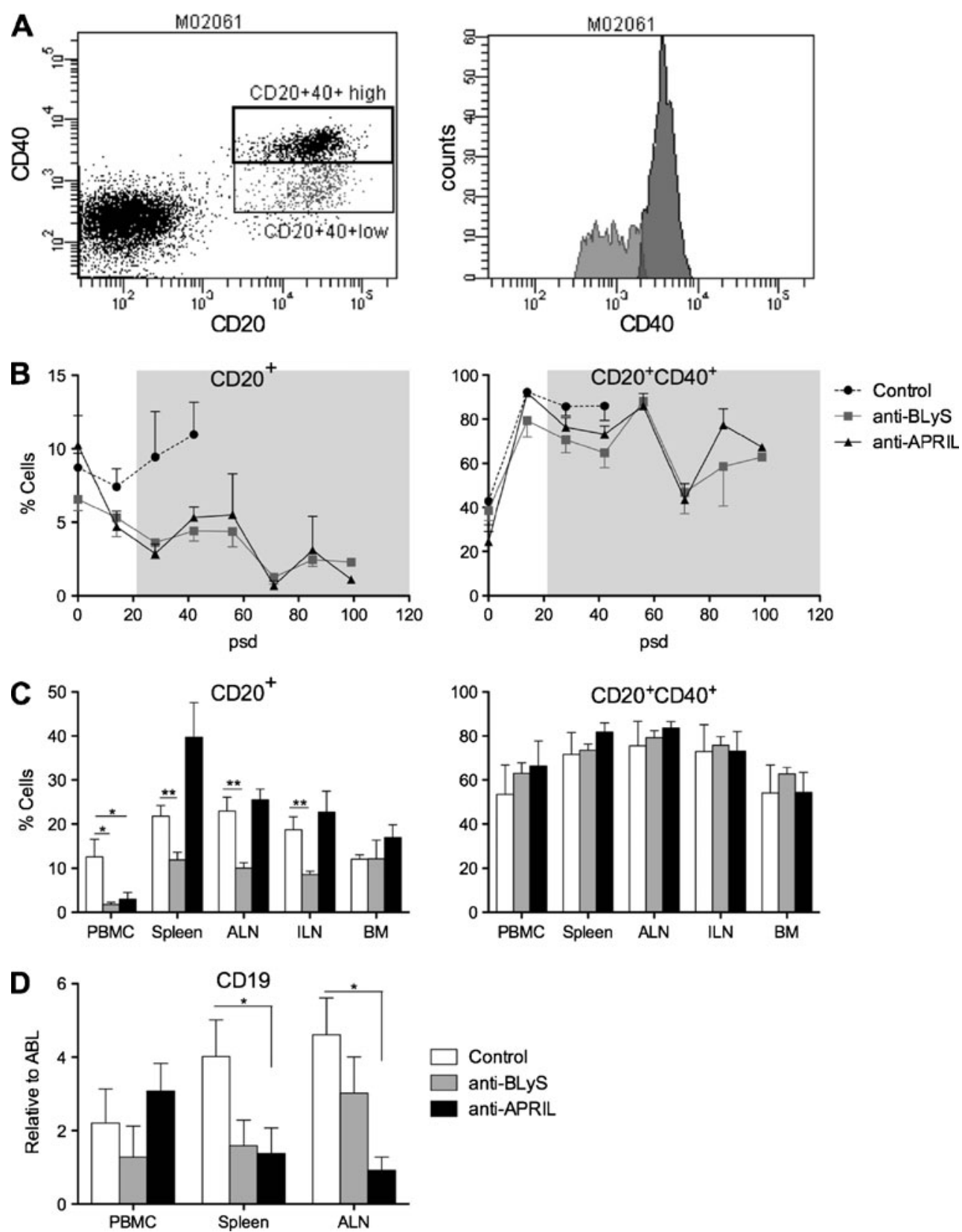

Control

anti-BLyS

anti-APRIL

Fig. 1 B cell depletion by anti-BLyS and anti-APRIL antibodies. a. $\mathrm{CD} 20+$ and $\mathrm{CD} 40+$ expression by PBMC was analysed by flow cytometry. Based on CD40 expression two populations could be defined, namely $\mathrm{CD} 20+\mathrm{CD} 40^{\text {high }}(13 \%$, dark shaded $)$ and $\mathrm{CD} 20+\mathrm{CD} 40+{ }^{\text {low }}$ (7 \%, light shaded). Depicted data are from monkey M02061 as a representative example. b. CD20+ (left panel) and CD20+CD40+ (right panel) expression was measured in $\mathrm{PBMC}$ collected at the indicated time points. The $\mathrm{CD} 20+\mathrm{CD} 40+$ includes the $\mathrm{CD} 20+\mathrm{CD} 40+{ }^{\text {high }}$ and $\mathrm{CD} 20+$ $\mathrm{CD} 40+{ }^{\text {low }}$ population The grey shaded area indicates the period of treatment, which was started at post sensitization day (psd) 21. Percentages on the $y$-axes are cell numbers expressed relative to the total analysed cell number (mean \pm SEM). CD20 $+B$ cells are reduced by the anti-BLyS and anti-APRIL treatment compared to untreated monkeys, but this is not the case for $\mathrm{CD} 20+\mathrm{CD} 40+$ mature B cells. c. MNC were

subsets of circulating marmoset $\mathrm{CD} 20+$ cells expressing low CD40 ( $\pm 7 \%)$ or high CD40 ( $\pm 13 \%)$. Figure $1 \mathrm{~b}$ depicts the prepared from blood, spleen, ALN, ILN and BM at necropsy to measure the presence of CD20+ B cells (left panel) and CD20+CD40+ mature B cells (right panel). Given percentages on y-axes indicates the fraction of stained cells from the total measured cells (mean \pm SEM). In the antiBLyS treated group a significant decrease of CD20+ B cells was detected in all tested organs except BM. Anti-APRIL treatment had only in blood a significant effect on CD20+ B cells. For the CD20+CD40+ cells no differences were observed between the control and antibody treated groups. d. At necropsy also the expression levels of CD19 mRNA transcripts were measured in PBMC, spleen and ALN, showing a reduction in both antibody-treated group, although the differences with anti-APRIL were only significant for spleen and ALN. Data was normalized to the household gene $\mathrm{ABL}$ (mean $\pm \mathrm{SEM}$ ). ${ }^{*} p<0.05$ Mann Whitney $U$ test, treated group vs. control group

longitudinal analysis of both subsets after immunization with rhMOG/CFA, showing that the percentage CD20+ 
cells first decreased slightly in control monkeys followed by a clear increase. The percentage CD20+ cells decreased in the groups treated with anti-BLyS and anti-APRIL mAb. Interestingly CD20+ cells expressing high CD40 were not depleted by the treatment.

To assess whether the depletion of B cells was systemic and long lasting we analysed expression of CD20 and $\mathrm{CD} 40$ on $\mathrm{MNC}$ isolated from blood, spleen, axillary and inguinal lymph nodes and bone marrow collected at necropsy (Fig. 1c). In the anti-BLyS treatment group we observed significant reduction of $\mathrm{CD} 20+$ cells in blood and lymphoid organs, but not in the BM. In the antiAPRIL group a significant effect on $\mathrm{CD} 20+\mathrm{B}$ cells depletion was only observed in blood, whereas the percentage CD20+ cells seemed increased in the spleen. Again, the two antibodies had no detectable effect on the percentage of $\mathrm{CD} 20+\mathrm{CD} 40+$ cells.

The flow cytometry data for the anti-BLyS treated group were confirmed by the analysis of mRNA transcript levels for CD19 (Fig. 1d). However, we observed an unexplained discrepancy between the increased CD20 staining and reduced CD19 mRNA level in the spleen of anti-APRIL treated monkeys

Taken together these data show that the anti-BLyS antibody consistently decreases B cell number in blood, spleen and lymph nodes, while a variable effect of the anti-APRIL antibody was observed in the monkeys.
Fig. 3 Delay of EAE course by anti-BLyS and anti-APRIL treatment. a. Clinical scores are depicted of controls (left panel) and the two antibody treated groups, with anti-BlyS (middle panel) or anti-APRIL (right panel). The solid lines represent clinical scores (left y-axes) and the dotted line body weight loss relative to the immunization day, defined as post sensitization day (psd) 0 . Grey shaded boxes indicate the treatment period. All animals in the experiment developed clinically evident EAE (clinical score 2.0) and most of them were sacrificed with an EAE score of 3.0. However, monkey Mi016, M0169 and M05049 had to be sacrificed at an earlier time point due to the serious body weight loss. b. Survival curves depict the disease free survival time (time interval to development of EAE score 2.0; left panel) and overall survival (time interval to clinical end point; right panel). Disease free survival times were significantly prolonged in the anti-BLyS and anti-APRIL treated monkeys. The total survival was significantly prolonged by the anti-BLyS treatment, but the delay in anti-APRIL treated monkeys was not significant $(p=0,0646) .{ }^{*} p<0.05 ;{ }^{* *} p<0.001$ Log-rank test, treated group vs. control group

Plasma antibody levels as a surrogate marker of systemic B cell reduction

We tested plasma antibody levels against the immunizing rhMOG protein and two B cell epitope containing peptides, i.e. MOG24-46 and MOG54-76, as an independent biomarker of systemic B cell depletion. Similar to previous studies, IgM serum antibodies against rhMOG in control monkeys peak during a short time interval after the immunization. Serum IgG antibodies come up somewhat later and remain high. Essentially the same patterns are observed for
Fig. 2 Anti-BLyS treatment reduced antibody production. Plasma samples collected at two weeks interval and necropsy were tested with ELISA for the presence of IgM (a) and IgG (b) antibodies against the B-cell epitopes MOG24-46 and MOG54-76, and against intact rhMOG. In the anti-BLyS treated group, reduction of IgM and IgG levels were observed during the entire study, but in the anti-APRIL treated groups IgM as well as IgG remained high. Mann Whitney $U$ test has been performed but no significantly differences were observed
A
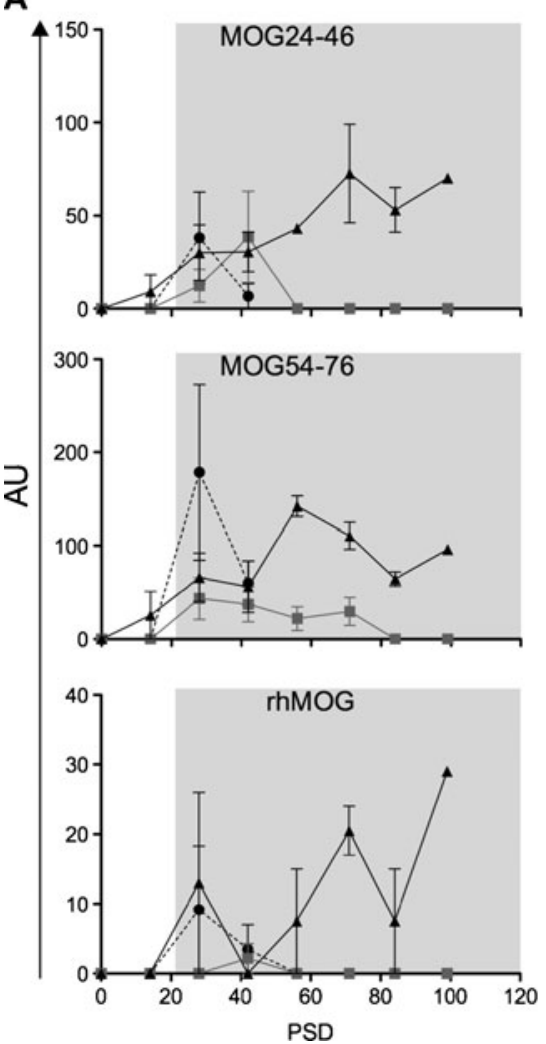
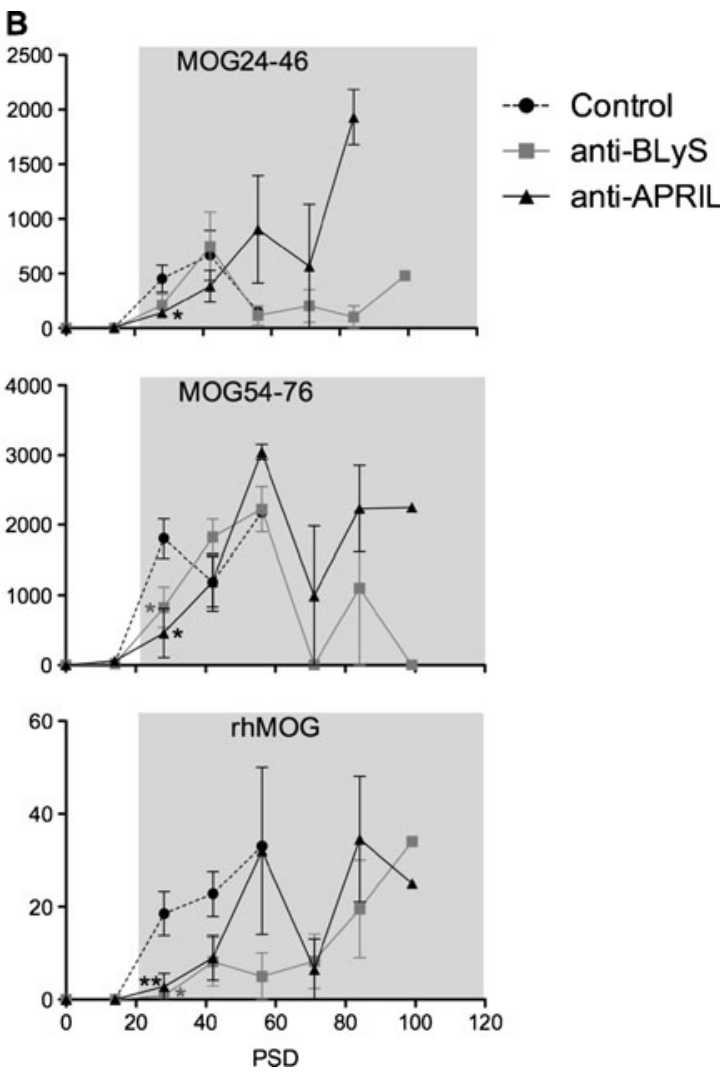


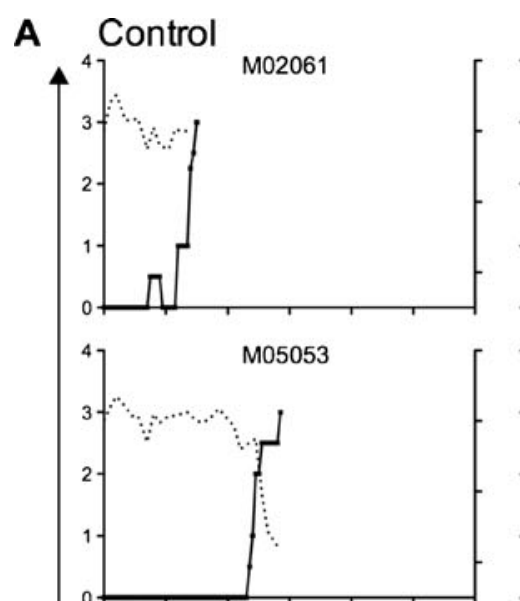

anti-BLyS
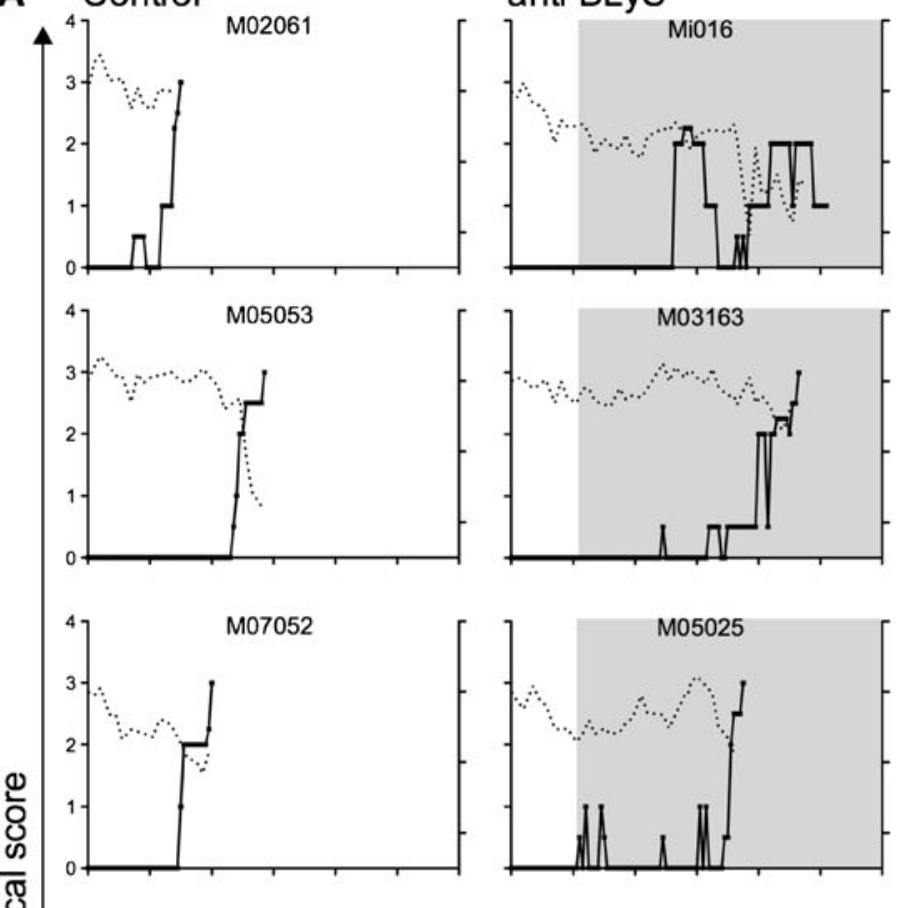

은
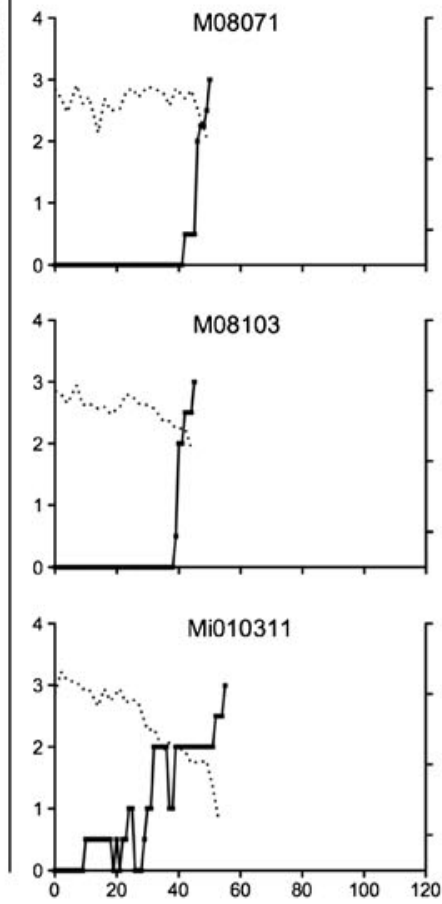
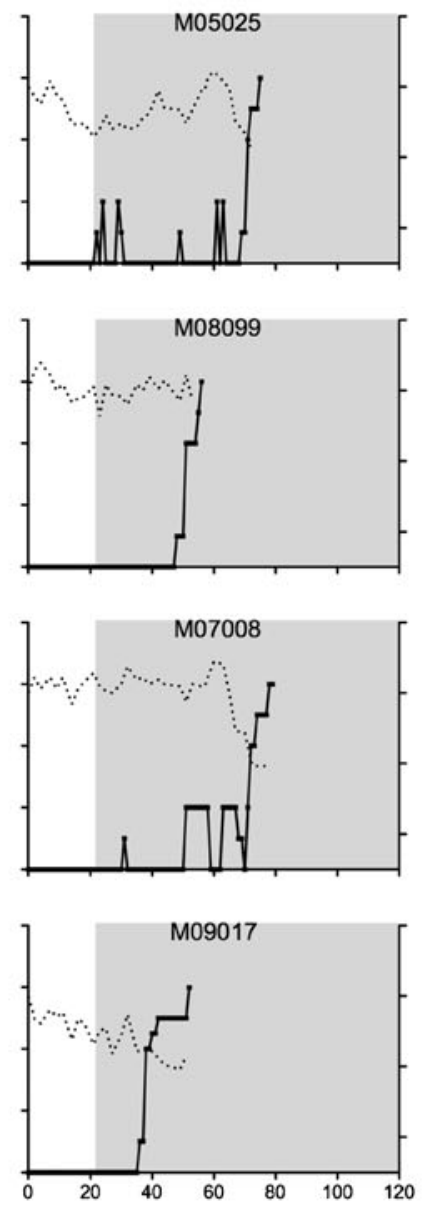

anti-APRIL
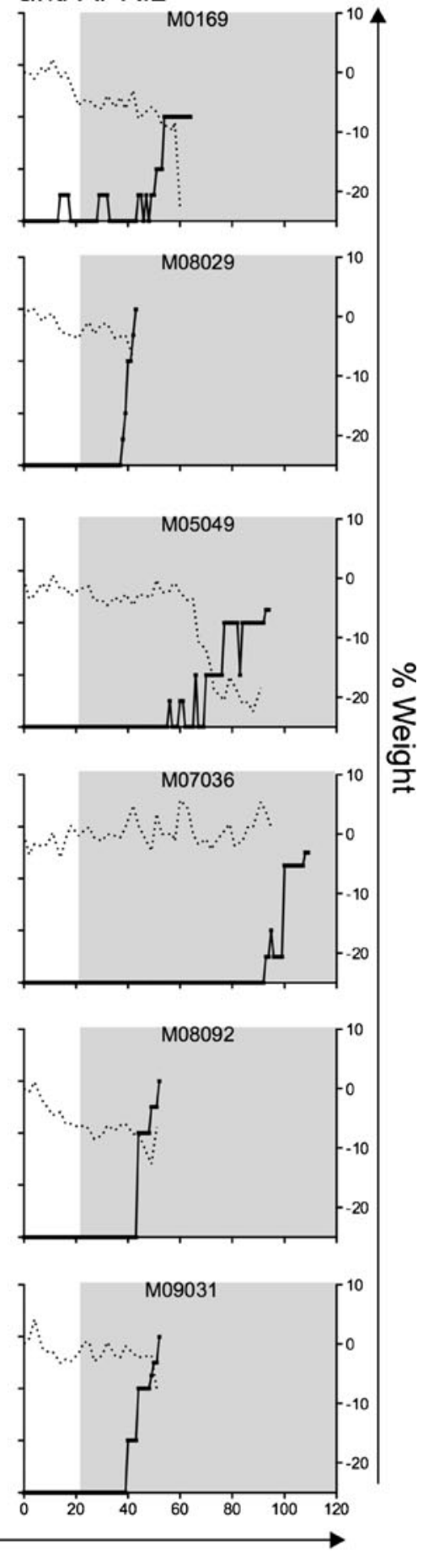

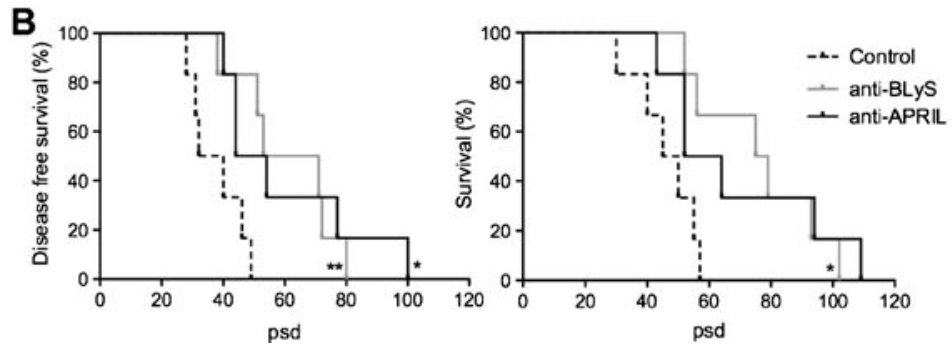


IgM (Fig. 2a) and IgG (Fig. 2b) antibodies against the two peptides. However, the antibody profiles differed clearly between the anti-BLyS and anti-APRIL treated groups. In general IgM antibody levels in the monkeys treated with anti-BLyS mAb remained markedly lower than in the group treated with anti-APRIL mAb. For IgG antibody levels this effect was less clear. The plasma level of anti-rhMOG IgG antibodies was clearly suppressed in the anti-BLyS treated group compared to the control group, whereas an inconsistent variable effect was observed for the anti-APRIL treated group.

Delayed EAE onset by anti-BLyS and anti-APRIL treatment

All animals in all the three groups developed clinically evident EAE and were sacrificed with a maximum score of 3, which was taken as the predefined ethical end-point. The graphs in Fig. 3a depict the clinical score and body weight loss of individual monkeys relative to the day of EAE induction (psd 0). Some monkeys (Mi010311, Mi016, M03163 and M05049) went into remission after a short period of visual problems reminiscent of optic neuritis. Two animals in the antiAPRIL group (M0169 and M05049) and one in the anti-BLyS group (Mi016) were sacrificed with an EAE score of 2. The reason for sacrifice, before the ethical end-point was reached, was the high bodyweight loss and low physical activity.

Comparison of the time interval to the onset of clinically evident EAE (score 2.0) of the anti-BLyS and antiAPRIL groups with the control group showed a significantly delayed disease onset (disease-free survival curves in Fig. 3b). The subsequent disease progression to the ethical end-point (score 3.0) was also delayed in both groups. However, the delay was statistically significant for the group treated with anti-BLyS mAb, but not for the anti-APRIL treated group $(p=0.0646)$.

Effect of the anti-BLyS and anti-APRIL mAbs on CNS pathology

Histological analysis of the spinal cord shows reduced inflammation in the anti-BLyS and anti-APRIL group compared to the controls. However, the differences in individual monkeys were too variable to reach statistical significance (Fig. 4a). The histology data also show a higher mean percentage demyelination of the brain in the anti-BLyS treated group, but also these differences were not statistically significant. In contrast, the anti-BLyS treated group displayed a significantly lower severity of spinal cord demyelination, while this was not observed for in the group treated with anti-APRIL mAb (Fig. 4b). Quantification of demyelination of the optic nerve suggested also a protective effect of the anti-BLyS and anti-APRIL mAbs. In the mAb treated groups $2 / 6$ monkeys showed $100 \%$ demyelination of the optic nerve while in the control group there were 4 control monkeys with $100 \%$ demyelination.

In conclusion, the histology data show a remarkable opposite effect of the anti-BLyS treatment on brain and spinal cord demyelination. This was not observed with the anti-APRIL mAb.

\section{Effect of the $\mathrm{mAb}$ on ex vivo $\mathrm{T}$ cell proliferation}

As a read-out for $\mathrm{T}$ cell proliferation we determined incorporation of $\left[{ }^{3} \mathrm{H}\right]$-thymidine (T-cell proliferation assay: TCPA) and CFSE vital dye dilution (Fig. 5).
Fig. 4 Reduced spinal cord demyelination in anti-BLyS treated monkeys. Formalinfixed tissue samples were stained to analyse the intensity of inflammation and demyelination. For each animal 8 slices were examined, which equals $6 \mathrm{~cm}^{2}$ in total. a. The number of infiltrated cells per $\mathrm{mm}^{2}$ is given for the spinal cord. The amount of demyelination is given for the spinal cord (b), optic nerve (c) and brain white matter (d). A significant treatment effect was only observed for the spinal cord of anti-BLyS treated animals. ${ }^{*} p<0.05$ Mann-Whitney U test, antibody treated group vs. control group
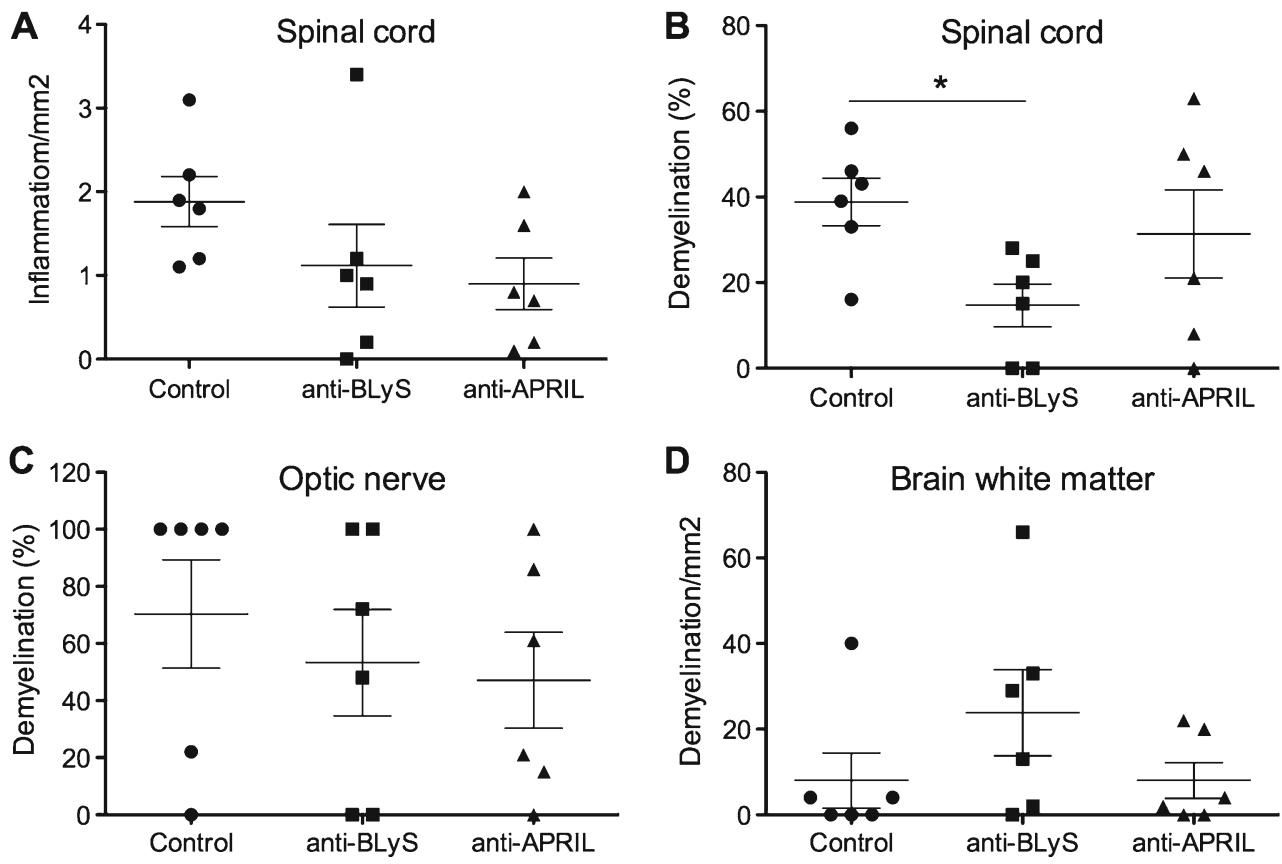

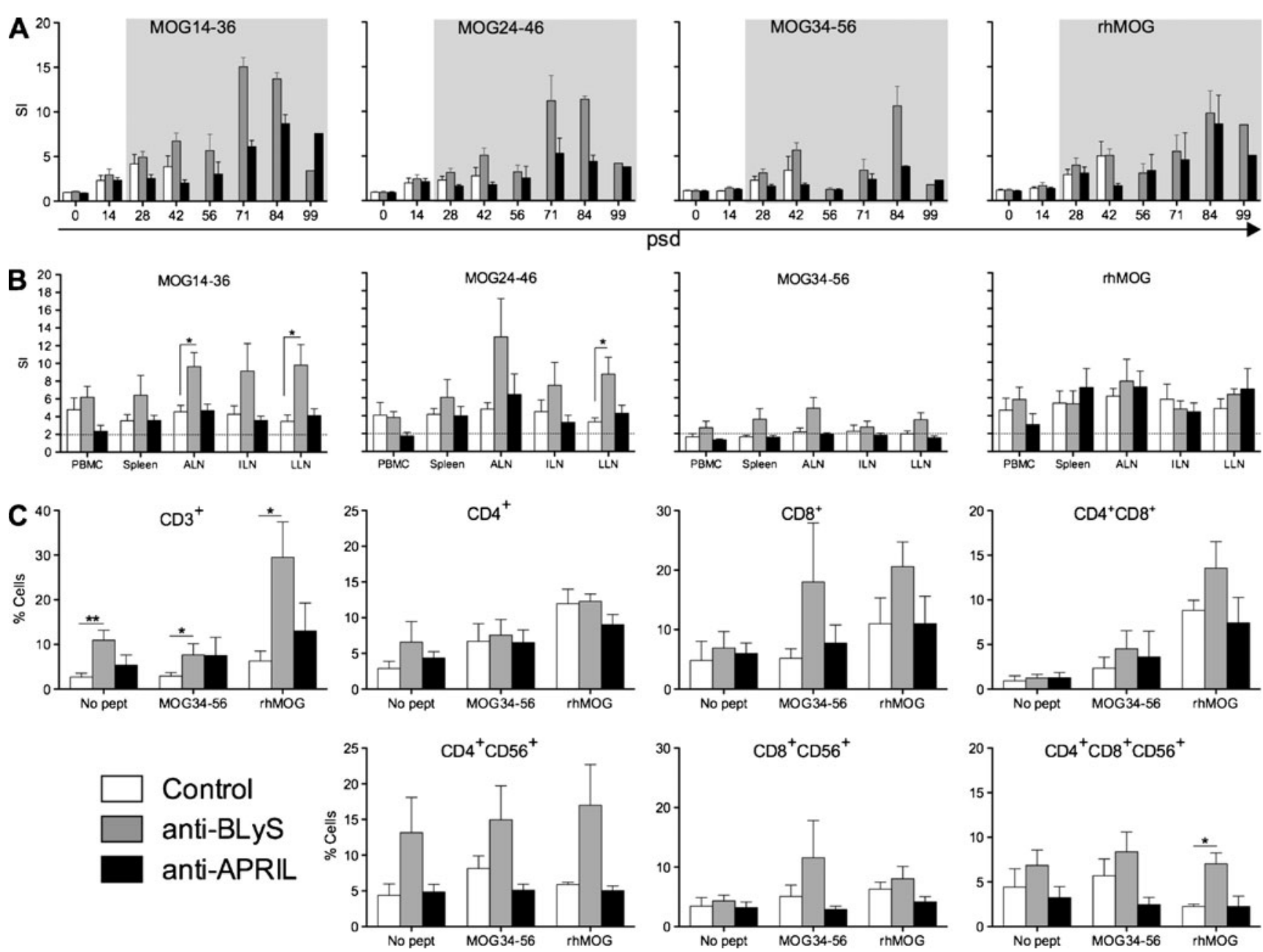

Fig. 5 Modulation of T cell proliferation in anti-BlyS and anti-APRIL treated monkeys. a. PBMC were isolated at the indicated time points (psd; post sensitization day) and assayed for the response to stimulation with rhMOG or 23-mer synthetic peptides containing previously identified dominant MOG T cell epitopes, i.e. MOG14-36, MOG24-46 and MOG34-56. The read-out was incorporation of $\left[{ }^{3} \mathrm{H}\right]$-thymidine during the final $18 \mathrm{~h}$ of 3 days culture. Data on the left panel show the stimulation index (SI). Grey shaded boxes indicate the period of treatment. T cell proliferation increased after immunization, and was significantly enhanced during the anti-BLyS treatment, but was reduced during antiAPRIL treatment. b. At necropsy the incorporation of $\left[{ }^{3} \mathrm{H}\right]$-thymidine

was measured as a read-out for proliferation in PBMC, spleen, ALN, ILN and LLN against the same MOG antigens as described under (A). c. Proliferated T cells in blood and lymphoid organs were phenotyped using the CFSE diluting assay. Data are shown of MNC derived from spleen, as a representative example. Stimulation with MOG34-56 and rhMOG are depicted. The y-axes indicates the percentage proliferated cells; CD4+, $\mathrm{CD} 8+$ and double positive for CD4 and CD8 were first gated within the $\mathrm{CD} 3+$ proliferated population, next for $\mathrm{CD} 4+\mathrm{CD} 56+, \mathrm{CD} 8+\mathrm{CD} 56+$ and $\mathrm{CD} 4+\mathrm{CD} 8+\mathrm{CD} 56+$, respectively. Data are presented as mean $\pm \mathrm{SEM} . * p$ $<0.05$ Mann Whitney U test, antibody treated group vs. control group

TCPA Figure 5a shows the longitudinal proliferation of PBMC against the immunizing rhMOG protein, the peptides MOG14-36 and MOG24-46, which contain the MOG24-36 epitope of early acting Caja-DRB*W1201 restricted CD4+ Th1 cells (Brok et al. 2000) and MOG34-56, which contains the MOG40-48 epitope of late acting Caja-E restricted $\mathrm{CD} 4+\mathrm{CD} 8+$ cytotoxic $\mathrm{T}$ lymphocyte (CTL) (Kap et al. 2008; Jagessar et al. 2012b). During the initial 40 days after immunization the differences between the three groups were relatively small. However, at psd 42 we observed a increase of PBMC proliferation in the control and anti-BLyS-treated

groups, while proliferation in the anti-APRIL treated group remained low. At 14 days later all control monkeys had been taken out of the experiment with clinically evident EAE. From psd 58 onwards PBMC proliferation in the anti-BLyS group was usually higher than in the monkeys treated with anti-APRIL mAb.

We also determined the proliferative response of MNC from blood and lymphoid organs at the height of the disease (Fig. 5b). The figure shows that the proliferation of MNC from spleen and LLN against the tested MOG peptides is consistently higher than that of the control and anti-APRILtreated monkeys. No significant difference was found for 

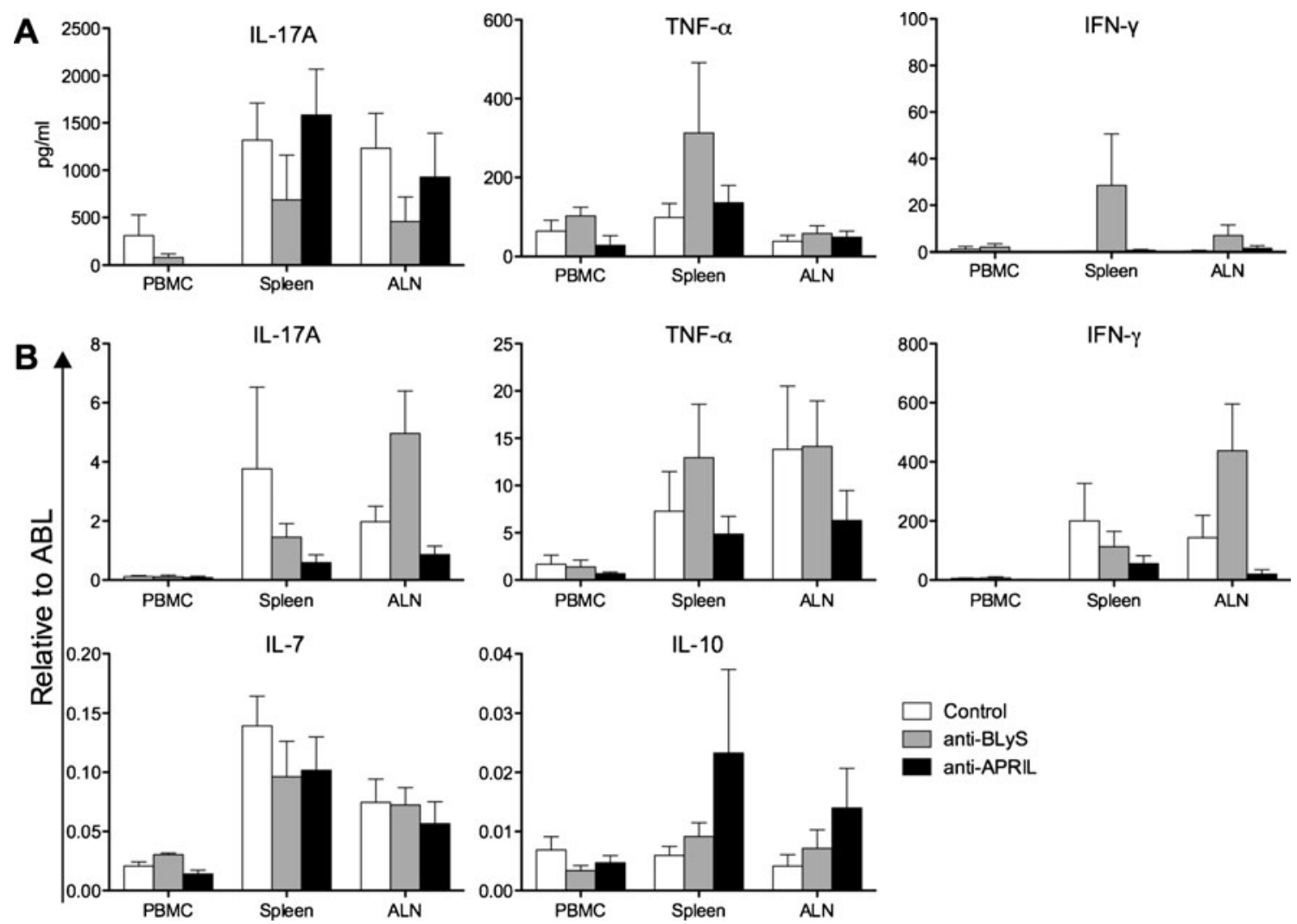

Fig. 6 Altered cytokine expression with anti-BLyS and anti-APRIL. a. At necropsy $\mathrm{MNC}$ were collected from blood and lymphoid organs and cultured for $48 \mathrm{~h}$ with a panel of MOG peptides and rhMOG. Levels of IL-17A (left panel), TNF- $\alpha$ (middle panel) and IFN- $\gamma$ (right panel) were measured in culture supernatants with ELISA (mean \pm SEM). Data is only shown of rhMOG stimulated MNC, since no high levels

the $\mathrm{MNC}$ proliferation against the immunizing rhMOG protein between the anti-BLyS treated and control monkeys.

CFSE dilution Flow cytometric analysis of CFSE labelled cells for dye dilution in combination with $\mathrm{mAb}$ staining was used to assess whether proliferation maps to a certain subset of $\mathrm{T}$ cells. We have focused on the response of spleen MNC against MOG34-56 as these contain the T cells that are the most likely culprit for the induction of neurological deficits (Kap et al. 2008) mainly localize in the spleen (Jagessar et al. 2010).

Freshly isolated spleen cells were stained with CFSE and subsequently cultured for 7 days without antigen and with MOG34-56 or rhMOG. Cells harvested from the cultures were incubated with selected monoclonal antibodies and binding was analysed by flow cytometry. The results are given in Fig. 5c. A first remarkable observation was that unstimulated CD3+ spleen MNC from monkeys treated with anti-BLyS $\mathrm{mAb}$ contain a significantly higher number of cells with CFSE dilution than $\mathrm{CD} 3+$ spleen MNC from control or anti-APRIL treated monkeys. This higher background proliferation in these animals localizes in the CD4+CD56+ subset. Seven days culture of the spleen cells with MOG34-56 did not of cytokines were measured in the MOG peptide stimulated cells. b. Cytokine mrRNA transcripts of IL-17A, TNF- $\alpha$, IFN- $\gamma$, IL-7 and IL10 were measured in PBMC, spleen and ALN. Data was normalized to the household gene $\mathrm{ABL}$ (mean $\pm \mathrm{SEM}$ ). Mann Whitney $U$ test was performed as statistical calculation, but no significant differences were observed

detectably enhance proliferation of $\mathrm{CD} 3+$ cells and the $\mathrm{CD} 3+\mathrm{CD} 4+(\mathrm{CD} 56+)$ subsets in all three groups, but proliferation of $\mathrm{CD} 3+\mathrm{CD} 8+$ and $\mathrm{CD} 3+\mathrm{CD} 8+\mathrm{CD} 56+$ cells was markedly, albeit non-significantly, enhanced in the anti-BLyS treated group. By contrast, 7 days stimulation of spleen cells with rhMOG induced significantly enhanced proliferation of $\mathrm{CD} 3+$ spleen cells, which localized to the $\mathrm{CD} 3+\mathrm{CD} 8+$, $\mathrm{CD} 3+\mathrm{CD} 4+\mathrm{CD} 8+$ and $\mathrm{CD} 3+\mathrm{CD} 4+\mathrm{CD} 8+\mathrm{CD} 56+$ subsets.

Collectively, these data show that the treatment with antiAPRIL had a less outspoken modulatory effect on the analysed cellular responses than the anti-BLyS treatment. This is in accordance with the postulate that the primary focus of APRIL activity is in the humoral arm of the immune system, whereas BLyS is involved in cellular as well as humoral immune mechanisms (Moisini and Davidson 2009).

Altered cytokine levels with anti-BLyS and anti-APRIL

The immunization of marmosets with rhMOG/CFA activates both Th1 and Th17 cells, which are both pathogenically relevant in this model, although they seem to operate in different pathways (Kap et al. 2010). We used ELISA to 
determine the ex vivo production of IL-17A, TNF- $\alpha$ and IFN- $\gamma$ proteins by MNC from blood, spleen and ALN after stimulation with the immunizing rhMOG antigen. Moreover, we determined the levels of mRNA transcripts for several cytokines to assess presence of functional MNC subsets: Th1 (TNF- $\alpha$ and IFN- $\gamma$ ), Th17 (IL-17A), Treg (IL-10) and IL-7 (B cells).

The profiles of cytokines secreted in the rhMOGstimulated cultures are displayed in Fig. 6a. This graph shows a trend towards reduced IL-17A production in all three analysed compartments of the anti-BLyS-treated animals, compared to both other groups, whereas the levels of TNF- $\alpha$ and IFN- $\gamma$ were increased. The rhMOG stimulation of MNC from the control and anti-APRIL treated monkeys induced essentially similar secretion levels of IL-17A, TNF- $\alpha$ and IFN- $\gamma$. However, due to the inter-individual variation in the outbred model, none of these effects reached statistical significance.

The analysis with cytokine specific qPCR of mRNA directly extracted from blood, spleen and ALN MNC shows inconsistent effects of the anti-BLyS and anti-APRIL treatment (Fig. 6b). Both antibodies induced reduced IL-17A and IFN- $\gamma$ transcript levels in spleen, whereas levels in ALN are increased in monkeys treated with anti-BLyS mAb but decreased by anti-APRIL treatment. Remarkably, in the anti-BLyS group increased transcript levels for TNF$\alpha$ were detected in spleen, whereas these were unchanged in ALN. In the anti-APRIL group TNF- $\alpha$ transcripts were reduced in ALN and unaltered in spleen. Interestingly, the transcript levels for IL-10 in spleen and ALN were enhanced in anti-APRIL treated monkeys, whereas the levels were unaltered in spleen and ALN from the anti-BLyS group. Finally, we observed marginally reduced IL-7 mRNA levels in spleen from the anti-BLyS and anti-APRIL treated monkeys, where these cytokines were unaltered in ALN.

In conclusion, both antibodies exerted a modulatory effect on the cytokine profiles of rhMOG-reactive $\mathrm{T}$ cells, although the direction of the effect can be opposite for several cytokines.

\section{Discussion}

The rhMOG/CFA induced EAE model in marmosets has presented itself as a useful preclinical model for translational research into MS pathogenesis ('t Hart et al. 2011). On the one hand the model shares well-documented features with the equivalent EAE models in mice and rats. On the other hand the model shares clinical and pathological features with MS, in particular the progressive course and the prominent involvement of grey matter demyelination ('t Hart et al. 2011).

The disease course of the model is not only variable, reflecting the genetic heterogeneity of the marmoset as an outbred species, but also highly complex, affecting the white and grey matter of the brain and spinal cord. As discussed elsewhere ('t Hart et al. 2011), the induction of inflammation and demyelination and the ensuing neurological deficits involves at least two pathways. The "canonical" pathway I seems to be primarily active in the initiation phase of the disease and involves the concerted action of MHC class IIrestricted Th1 cells and autoantibodies. In vivo activation (Brok et al. 2000)or adoptive transfer (Villoslada et al. 2001) of only the Th1 cells induces small inflammatory lesions without demyelination. Demyelination is effected when monkeys are immunized with B cell epitope containing rhMOG protein or by transfer of monoclonal antibody against MOG protein (Genain et al. 1995). It should be noted that pathway I is not strictly dependent of MOG, as it is also inducible with MOG-deficient myelin, whereas for the activation of pathway II, MOG seems indispensable (Jagessar et al. 2008). The "non-canonical" pathway II becomes likely engaged later in the pathogenic process and involves MHC class I-restricted effector memory natural killer-like cytotoxic T cells (NK-CTL) interacting with Th17 cells (Kap et al. 2008; Jagessar et al. 2010; Jagessar et al. 2012b). The MHC-class II $($ Caja-DRB*W1201) and MHC class I (Caja-E) restriction elements, respectively operating in pathways I (Brok et al. 2000) and II (Jagessar et al. 2012b) are both monomorphic in the common marmoset, explaining why the two pathways can be operational in all animals.

$\mathrm{B}$ cells have a pathogenic contribution to both pathways. The main role of B cells in the canonical pathway I is the production of autoantibodies against myelin, which elicit cellular and/or complement dependent cytotoxicity reactions. The primary role in the non-canonical pathway II, which is independent of autoantibodies, is antigen presentation to the NK-CTL that induces demyelination of grey and white matter without detectable involvement of autoantibodies. The latter role of B cells was shown in two independent experiments. One set of experiments demonstrated that depletion of B cells with the anti-CD20 antibody HuMab7D8 from marmosets at 21 days after the immunization with rhMOG/CFA abrogates the development of EAE symptoms (Kap et al. 2010) as well as of EAE pathology in the grey and white matter of the brain and spinal cord (Kap et al. 2011). This highly robust effect was associated with impaired activation of the cellular autoimmune mechanisms that mediate disease progression. A second set of experiments was performed in the novel MOG34-56/IFA EAE model in which white and grey matter demyelination is induced by peptide-specific NK-CTL without a detectable influence of autoantibodies (Jagessar et al. 2010; Jagessar et al. 2012b). In the same MOG34-56/IFA EAE model it was observed that depletion of $\mathrm{CD} 20+\mathrm{B}$ cells from 21 days after the immunization abrogates the development of EAE symptoms and pathology (submitted for publication).

We report here the effect on the rhMOG/CFA EAE model of two monoclonal antibodies against essential factors for B 
cell survival and differentiation. BLyS and APRIL have partially overlapping roles in B cell survival and differentiation involving at least 3 receptors, i.e. BCMA, TACI and BR3, which recognize homo-trimeric forms of BLyS and APRIL (Miller et al. 2006). BLyS binds to all three receptors, but with highest affinity for BR3. APRIL does not bind BR3 and has about 100-fold higher affinity for BCMA than BLyS. TACI binds both factors with comparable affinity.

The results of the current study show that anti-BLyS and anti-APRIL administration to rhMOG/CFA immunized marmosets induced depletion of CD20 + B cells from blood at a similar rate and depth. Similar to observations in cynomolgus monkeys the depletion with anti-BLyS mAb was less fast or profound than with anti-CD20 mAb (Halpern et al. 2006). In the monkeys treated with anti-BLyS, but not in those treated with anti-APRIL we observed reduction of CD20+ B cells in spleen and lymph nodes. With qPCR analysis it was also shown that CD19 transcript levels were reduced in spleen and ALN of anti-BLyS as well as antiAPRIL treated monkeys. It is difficult to explain these discrepancies although it should be noted that CD20 is an exclusive marker of the B cell lineage, whereas CD19 is also expressed by the follicular dendritic cells that populate lymphoid organs. Interestingly, we observed no depletion by anti-BLyS or anti-APRIL mAb of the CD20+CD40+ subset. This subset is actively engaged in the EAE pathogenesis as illustrated by the finding that administration of antagonist anti-CD40 mAb suppressed EAE development in the rhMOG/CFA model (Boon et al. 2001). However, disease activity within the CNS was only partly suppressed. This is a remarkable difference with the robust clinical (Kap et al. 2010) and pathological (Kap et al. 2011) effect of anti$\mathrm{CD} 20 \mathrm{mAb}$ treatment in the rhMOG/CFA model, in which complete depletion of the CD20+CD40- and CD20+CD40 + subsets was observed. Collectively, these data show that for an optimal clinical effect of B cell targeting antibodies in the rhMOG/CFA model probably both subsets of B cells have to be depleted.

The separate antibody-mediated inhibition of BLyS and APRIL exerted comparable clinical effects in the EAE model, although several differences at the immunological and pathological level were observed. Neutralization of BLyS or APRIL caused a significantly delayed onset of overt clinical EAE (EAE score 2.0, ataxia). However, the effect on the time to the study end-point (EAE score 3.0, hemi-/paraplegia) was statistically significant only for the group treated with anti-BLyS antibody. Moreover, in the monkeys treated with anti-BLyS, but not in those treated with anti-APRIL, we observed significantly reduced demyelination of spinal cord. These discrepant effect may be explained by the fact that the anti-BLyS antibody targets not only processes in the periphery, i.e. B cell survival, but also in the CNS, i.e. neuronal outgrowth. BLyS is produced within the CNS by reactive astrocytes and exerts via NgR1 similar effects on neurons as the natural ligand Nogo66 (Zhang et al. 2009). To our knowledge, such non-immunological effects in the EAE model have not been reported for APRIL.

The two mAbs were found to modulate, albeit in a different manner, cellular autoimmune reactions involved in the EAE pathogenesis. This was observed in regular proliferation assays using MNC isolated from different immune compartments; response patterns of $\mathrm{T}$ cell subsets assessed by CFSE vital dye dilution and the cytokine profiles. We observed in the anti-BLyS-treated group enhanced proliferation of MNC from blood and lymphoid organs against MOG peptides $14-36$ and 24-46, which both contain the epitope MOG24-36 that is presented by a ubiquitously expressed monomorphic Caja-DRB*W1201 allele to Th1 cells (Brok et al. 2000; Doxiadis et al. 2006). The higher production of TNF- $\alpha$ and IFN- $\gamma$ by the rhMOGstimulated splenocytes supports this conclusion. We observed lower production of IL-17A than in the other two groups i.e. anti-APRIL and the controls. Phenotyping of proliferating cells via CFSE vital dye dilution and monoclonal antibody staining shows that $\mathrm{CD} 3+\mathrm{T}$ cells from anti-BLyS treated monkeys displayed higher proliferative activity than those from the other two groups, which are localized mostly within the CD4+CD56+ subset. However, the rhMOG and MOG3456-stimulated proliferation are localized mainly in the $\mathrm{CD} 8+$, $\mathrm{CD} 4+\mathrm{CD} 8+, \mathrm{CD} 8+\mathrm{CD} 56+$ subsets. Importantly, the reactivity of the $\mathrm{CD} 4+\mathrm{CD} 8+\mathrm{CD} 56+$ subset to antigenic stimulation, which is the main source of the autoreactive $\mathrm{T}$ cells cytotoxic activity in the marmoset EAE model (Jagessar et al. 2010; Jagessar et al. 2012b), is not increased by the treatment.

In the monkeys treated with the anti-APRIL mAb we did not observe marked differences with the control monkeys at the level of proliferation by MNC from blood, spleen or lymph nodes, neither in the TCPA test nor with CFSE vital dye dilution. However, the cytokine analyses showed the lowest expression of pro-inflammatory cytokines IL-17A, IFN- $\gamma$ and TNF- $\alpha$ mRNA transcripts concomitant increased expression of anti-inflammatory IL-10 mRNA in this group.

In conclusion, the treatment with anti-BLyS and antiAPRIL antibody, which was started at a relatively late stage (day 21 post immunization), results in a significant delay of EAE onset and progression. Due to the heterogeneity between individual monkeys, which is inherent to this outbred model, differences between investigated variables in the three groups often did not reach statistical significance. This implies that they should be interpreted with caution as only trends can be indicated. The clinical effect of the therapeutic antibodies seems to be based on different mechanisms. The anti-BLyS treated group displays reduced antibody levels against rhMOG and MOG peptides, together with reduced Th17 and increased Th1 activation. We hypothesize that treatment with the anti-BLyS antibody may impair both the canonical and the 
non-canonical pathogenic pathway. Besides this immunomodulatory effect, the depletion of BLyS could also have consequences inside the CNS, such as removal of axonal outgrowth inhibition. For the anti-APRIL antibody such central effects are not known, which may explain why the disease progression after initiation (score 2.0 to 3.0) is not significantly affected. However, the antibody has modulatory effects on the autoimmune reaction, most notably a reduction of $\mathrm{Th} 1$ and Th17 signature cytokine transcripts and an increase of IL-10 mRNA. This may suggest that the inhibitory activity of the anti-APRIL mAb mainly affects pathway I (B cells/autoantibodies), and is based on skewing from a pro- to antiinflammatory $\mathrm{T}$ cell profile. Further research should demonstrate whether this is indeed the case.

Acknowledgement The authors thank the Animal Science Department for biotechnical assistance, in particular Jeroen Sollie, Mariska van Etten and Tom Haaksma. Conflicts of interest: At the time that the experiments were executed co-authors Thi-Sau Migone and Matt Develaraja were employees of Human Genome Sciences, which sponsored the study and provided the anti-BLyS and anti-APRIL antibodies. The other authors do not report conflicts of interest.

Open Access This article is distributed under the terms of the Creative Commons Attribution License which permits any use, distribution, and reproduction in any medium, provided the original author(s) and the source are credited.

\section{References}

't Hart BA, Gran B, Weissert R (2011) EAE: imperfect but useful models of multiple sclerosis. Trends Mol Med 17:119-125

Bacchetti P, Deeks SG, McCune JM (2011) Breaking free of sample size dogma to perform innovative translational research. Sci Transl Med 3:87ps24

Barun B, Bar-Or A (2012) Treatment of multiple sclerosis with AntiCD20 antibodies. Clin Immunol 142:31-37

Boon L, Brok HP, Bauer J, Ortiz-Buijsse A, Schellekens MM, Ramdien-Murli S, Blezer E, van Meurs M, Ceuppens J, de Boer M, 't Hart BA, Laman JD (2001) Prevention of experimental autoimmune encephalomyelitis in the common marmoset (Callithrix jacchus) using a chimeric antagonist monoclonal antibody against human CD40 is associated with altered B cell responses. J Immunol 167:2942-2949

Brok HP, Uccelli A, Kerlero De Rosbo N, Bontrop RE, Roccatagliata L, de Groot NG, Capello E, Laman JD, Nicolay K, Mancardi GL, Ben-Nun A, 't Hart BA (2000) Myelin/oligodendrocyte glycoprotein-induced autoimmune encephalomyelitis in common marmosets: the encephalitogenic T cell epitope pMOG24-36 is presented by a monomorphic MHC class II molecule. J Immunol 165:1093-1101

Carson KR, Focosi D, Major EO, Petrini M, Richey EA, West DP, Bennett CL (2009) Monoclonal antibody-associated progressive multifocal leucoencephalopathy in patients treated with rituximab, natalizumab, and efalizumab: a Review from the Research on Adverse Drug Events and Reports (RADAR) Project. Lancet Oncol 10:816-824

Daridon C, Youinou P, Pers JO (2008) BAFF, APRIL, TWE-PRIL: who's who? Autoimmun Rev 7:267-271
Doxiadis GG, van der Wiel MK, Brok HP, de Groot NG, Otting N, 't Hart BA, 't Hart BA, van Rood JJ, Bontrop RE (2006) Reactivation by exon shuffling of a conserved HLA-DR3-like pseudogene segment in a New World primate species. Proc Natl Acad Sci USA 103:5864-5868

Genain CP, Nguyen MH, Letvin NL, Pearl R, Davis RL, Adelman M, Lees MB, Linington C, Hauser SL (1995) Antibody facilitation of multiple sclerosis-like lesions in a nonhuman primate. J Clin Invest 96:2966-2974

Halpern WG, Lappin P, Zanardi T, Cai W, Corcoran M, Zhong J, Baker KP (2006) Chronic administration of belimumab, a BLyS antagonist, decreases tissue and peripheral blood B-lymphocyte populations in cynomolgus monkeys: pharmacokinetic, pharmacodynamic, and toxicologic effects. Toxicol Sci: An official journal of the Society of Toxicology 91:586-599

Jagessar SA, Smith PA, Blezer E, Delarasse C, Pham-Dinh D, Laman JD, Bauer J, Amor S, 't Hart BA (2008) Autoimmunity against myelin oligodendrocyte glycoprotein is dispensable for the initiation although essential for the progression of chronic encephalomyelitis in common marmosets. J Neuropathol Exp Neurol 67:326-340

Jagessar SA, Kap YS, Heijmans N, van Driel N, van Straalen L, Bajramovic JJ, Brok HP, Blezer EL, Bauer J, Laman JD, 't Hart BA (2010) Induction of progressive demyelinating autoimmune encephalomyelitis in common marmoset monkeys using MOG3456 peptide in incomplete freund adjuvant. J Neuropathol Exp Neurol 69:372-385

Jagessar SA, Gran B, Heijmans N, Bauer J, Laman JD, ’t Hart BA, Constantinescu CS (2012a) Discrepant effects of human interferon-gamma on clinical and immunological disease parameters in a novel marmoset model for multiple sclerosis. J Neuroimmune Pharmacol 7:253-265

Jagessar SA, Heijmans N, Blezer EL, Bauer J, Blokhuis JH, Wubben JA, Drijfhout JW, van den Elsen PJ, Laman JD, ’t Hart BA (2012b) Unravelling the T-cell-mediated autoimmune attack on CNS myelin in a new primate EAE model induced with MOG34-56 peptide in incomplete adjuvant. Eur J Immunol 42:217-227

Kap YS, Smith P, Jagessar SA, Remarque E, Blezer E, Strijkers GJ, Laman JD, Hintzen RQ, Bauer J, Brok HP, 't Hart BA (2008) Fast progression of recombinant human myelin/oligodendrocyte glycoprotein (MOG)-induced experimental autoimmune encephalomyelitis in marmosets is associated with the activation of MOG3456-specific cytotoxic T cells. J Immunol 180:1326-1337

Kap YS, van Driel N, Blezer E, Parren PW, Bleeker WK, Laman JD, Craigen JL, 't Hart BA (2010) Late B cell depletion with a human anti-human CD20 IgG1 kappa monoclonal antibody halts the development of experimental autoimmune encephalomyelitis in marmosets. J Immunol 185:3990-4003

Kap YS, Bauer J, Driel NV, Bleeker WK, Parren PW, Kooi EJ, Geurts JJ, Laman JD, Craigen JL, Blezer E, 't Hart BA (2011) B-cell depletion attenuates white and gray matter pathology in marmoset experimental autoimmune ancephalomyelitis. J Neuropathol Exp Neurol 70:992-1005

Kerlero de Rosbo N, Hoffman M, Mendel I, Yust I, Kaye J, Bakimer R, Flechter S, Abramsky O, Milo R, Karni A, Ben-Nun A (1997) Predominance of the autoimmune response to myelin oligodendrocyte glycoprotein (MOG) in multiple sclerosis: reactivity to the extracellular domain of MOG is directed against three main regions. Eur J Immunol 27:3059-3069

Lassmann H, Bruck W, Lucchinetti CF (2007) The immunopathology of multiple sclerosis: an overview. Brain Pathol 17:210-218

Laws PM, Warren RB (2011) Ustekinumab for the treatment of psoriasis. Expert Rev Clin Immunol 7:155-164

Lopez-Diego RS, Weiner HL (2008) Novel therapeutic strategies for multiple sclerosis-a multifaceted adversary. Nat Rev Drug Discov 7:909-925 
Miller JP, Stadanlick JE, Cancro MP (2006) Space, selection, and surveillance: setting boundaries with BLyS. J Immunol 176:6405-6410

Moisini I, Davidson A (2009) BAFF: a local and systemic target in autoimmune diseases. Clin Exp Immunol 158:155-163

Pers JO, Daridon C, Bendaoud B, Devauchelle V, Berthou C, Saraux A, Youinou P (2008) B-cell depletion and repopulation in autoimmune diseases. Clin Rev Allergy Immunol 34:50-55

Segal BM, Constantinescu CS, Raychaudhuri A, Kim L, Fidelus-Gort R, Kasper LH (2008) Repeated subcutaneous injections of IL12/ 23 p40 neutralising antibody, ustekinumab, in patients with relapsing-remitting multiple sclerosis: a phase II, double-blind, placebo-controlled, randomised, dose-ranging study. Lancet Neurol 7:796-804

Smith PA, Heijmans N, Ouwerling B, Breij EC, Evans N, van Noort JM, Plomp AC, Delarasse C, 't Hart BA, Pham-Dinh D, Amor S (2005) Native myelin oligodendrocyte glycoprotein promotes severe chronic neurological disease and demyelination in Biozzi $\mathrm{ABH}$ mice. Eur J Immunol 35:1311-1319

Teeling JL, French RR, Cragg MS, van den Brakel J, Pluyter M, Huang H, Chan C, Parren PW, Hack CE, Dechant M, Valerius T, van de Winkel JG, Glennie MJ (2004) Characterization of new human CD20 monoclonal antibodies with potent cytolytic activity against non-Hodgkin lymphomas. Blood 104:17931800

Villoslada P, Abel K, Heald N, Goertsches R, Hauser SL, Genain CP (2001) Frequency, heterogeneity and encephalitogenicity of $\mathrm{T}$ cells specific for myelin oligodendrocyte glycoprotein in naive outbred primates. Eur J Immunol 31:2942-2950

Zhang L, Zheng S, Wu H, Wu Y, Liu S, Fan M, Zhang J (2009) Identification of BLyS (B lymphocyte stimulator), a non-myelinassociated protein, as a functional ligand for Nogo-66 receptor. J Neurosci 29:6348-6352 